\title{
UHF Class-E Power Amplifier Design for Wide Range Variable Resistance Operation
}

\author{
David Vegas, María Pampín, Jose-Ramon Perez-Cisneros, M. Nieves Ruiz, Angel Mediavilla, José A. García \\ Department of Communications Engineering, University of Cantabria, 39005 Santander, Spain
}

\begin{abstract}
This paper presents a simple switch model for a GaN HEMT device, extracted to estimate the output power and efficiency load-pull contours when the transistor is used in a UHF class-E power amplifier (PA). The impact of model parameters on the theoretical achievable efficiency versus output power backoff (PBO) profile is considered, to then be used in a loadinsensitive class-E design methodology. A simple lumped element terminating network, derived from [1], was selected to approximate the desired zero voltage switching (ZVS) operation along a wide range of resistive loads. A $700 \mathrm{MHz}$ outphasing transmitter, amenable to be transformed into a resonant dc/dc power converter, has been implemented for validation. Drain efficiency peaks of $82.2 \%$ and $78 \%$ have been measured for each application case, with values above $70 \%$ and $60 \%$ at $10 \mathrm{~dB}$ of backoff and $30 \%$ of nominal de output power, respectively.
\end{abstract}

Index Terms- Class-E, Chireix, efficiency, load modulation, load-pull, outphasing, power amplifier, power converter, UHF.

\section{INTRODUCTION}

As wireless communication systems advance to the fifth generation, the design of power efficient transmitter architectures is more challenging than ever so as to handle spectrally efficient signals with unprecedented peak-to-average power ratio (PAPR) values. Up to the low microwave bands, most promising results are achieved by techniques based on dynamic load modulation and/or dynamic biasing concepts $[2,3]$.

Among the load modulating schemes, the outphasing technique, originally proposed by Chireix [4], has recently received increased attention due to the introduction of highefficiency class-E [5] PAs. This single-switch inverter has also become attractive to power supply specialists, interested in operating their $\mathrm{dc} / \mathrm{dc}$ converters at higher frequencies [6]. The envelope amplifier is probably the most illustrative example of the need for fast response power converters in wireless communication transmitters.

The traditional class-E PA in [5] is, by nature, highly sensitive to variations in load resistance. This is the reason why a lot of efforts have been put into the synthesis of topologies that maintain ZVS operation over a wide range of resistive loads. In this paper, a simple switch model for a GaN HEMT device is presented, aimed to be used in the design of a loadindependent class-E PA. A compact lumped element drain terminating network is shown to provide competitive figures of merit for both application cases: a class-E based outphasing transmitter and a class- $\mathrm{E}^{2}$ resonant $\mathrm{dc} / \mathrm{dc}$ converter [7].

\section{Class-E Operation UNDER VARIABLE LOAD}

The load-pull contours for an ideal class-E PA were derived by Raab in [8]. A unity efficiency was proved to be theoretically possible along a locus with variable output voltage amplitude, leading later to the proposal of an asymmetric outphasing scheme [9]. The impact of the ON-state and OFF-state resistances on the voltage and current waveforms has been addressed by different authors along the years, starting as early as in [10]. Prediction of class-E load-pull contours is currently possible with advanced nonlinear models and mature harmonic balance simulators. Besides not necessarily providing a direct relation with the corresponding loss mechanisms, these models may lead to convergence problems at some extreme terminating conditions, or may be inaccurate when reproducing the linear and inverse operating regions of a FET.

\section{A. Switch-based GaN HEMT Model}

A simple model was extracted for a CGH35030F GaN HEMT device from Wolfspeed. In order to easily check its accuracy for load-pull prediction, the model parameters were obtained from simulations using the supplier nonlinear model. Its schematic is presented in Fig. 1.

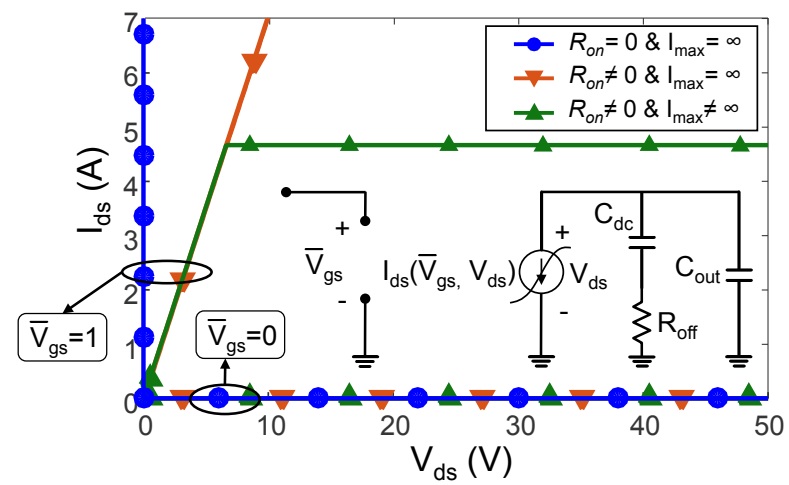

Fig. 1. Switch-based model schematic and $\mathrm{I} / \mathrm{V}$ characteristics for different cases: ideal switch, non-zero $R_{o n}$ and non-zero $R_{o n}$ with finite $I_{\max }$. 


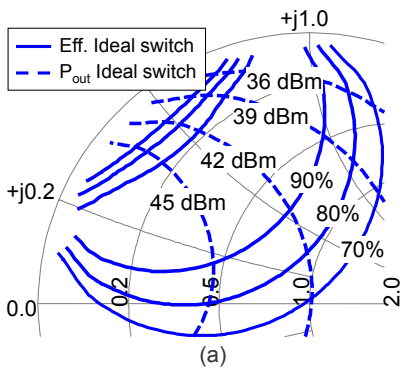

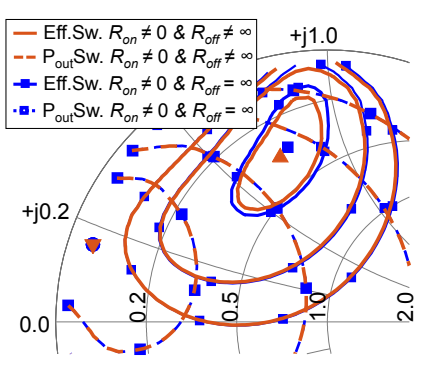

(b)

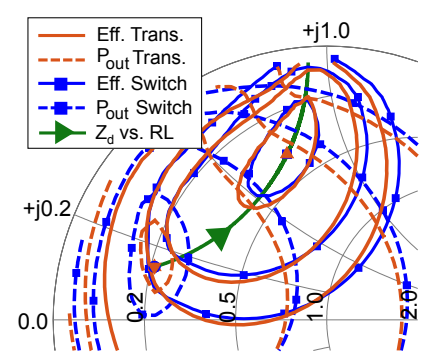

(c)

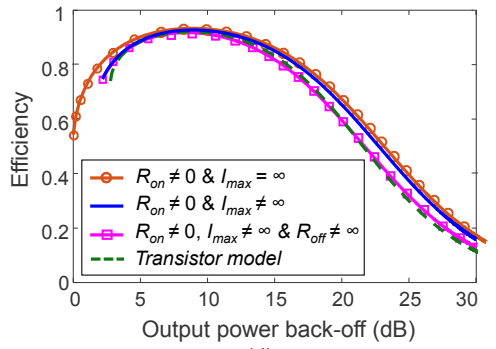

(d)

Fig. 2. a)-c) Comparison of output power and efficiency load-pull contours, obtained from simulations, for the proposed switch model ( $C_{\text {out }} \neq 0$ in all the cases) and the supplier nonlinear model. d) Contribution of model parameters to the efficiency vs. PBO profile along the optimum $Z_{d}\left(R_{L}\right)$ path in Fig. $2 \mathrm{c}$.

The current source value is directly proportional to a normalized gate-to-source voltage, $\bar{V}_{g s}$, taking one of two possible values ( 0 for the OFF-state, 1 when conducting). A piecewise function describes its dependence on the drain-to-source voltage, with a linear characteristic below the knee voltage, while constant above it. Attending to the values for the slope, $1 / R_{o n}$, and the current limit, $I_{\max }$, different cases may be evaluated, as also depicted in Fig. 1. The output equivalent capacitor, $C_{\text {out }}$, is complemented with an OFF-state resistance in parallel, $R_{\text {off }}$, not contributing in dc. Very good estimates for $R_{\text {off }}$ and $C_{\text {out }}$ may be directly extracted from the value of the $\mathrm{S}_{22}$ parameter, with the device biased at the selected drain voltage $\left(V_{D S}=28\right.$ V) and slightly below pinch-off $\left(V_{G S}=-3.5 \mathrm{~V}\right)$. In a GaN HEMT device, with low-frequency dispersion effects associated to self-heating and trap-states, $R_{o n}$ and $I_{\max }$ should be derived from the temperature-dependent I/V characteristics in pulsed regime.

\section{B. Load-pull Contours}

Load-pull simulations were completed for different cases (Fig. 2). The contours for an ideal switch in Fig. 2a, transform into those in Fig. 2b when including the impact of $R_{o n}$ and $R_{\text {off }}$. The ON-state resistance and the associated conduction losses have a major influence on the efficiency contours, with the finite OFF-state resistance at RF only contributing at low output power values, as expected. The current limit, added in Fig. 2c, is required for a good prediction of the output power contours, as in class-B PAs $[11,12]$. Using $C_{o u t}, R_{o n}, R_{o f f}$ and $I_{\max }$, the contours obtained from the device nonlinear model in Fig. 2c may be fitted with good accuracy.

The existence of an optimum path or locus for efficient operation with controlled output power [8] is evident from Fig. 2c. The desired ZVS condition is approximated along this path, minimizing the switching loss contribution by $C_{\text {out }}$. The influence of the rest of parameters on the efficiency vs. output power backoff profile along this locus was studied in detail and is represented in Fig. 2d. Several conclusions can be extracted: $R_{o n}$ is determinant over the efficiency performance, $I_{\max }$ sets the output power capability of the device and, finally, $R_{\text {off }}$ impacts the efficiency only at high output PBO. Simply adding the current limit to the resistance in conduction state, an acceptable prediction may be obtained.

\section{LOAD-INDEPENDENT CLASS-E PA DESIGN}

As alternative to the addition of transmission lines or equivalent networks in [9], a load-independent operation of the traditional class-E PA may be approximated if properly incorporating an inductive impedance inverter as in [1]. Originally proposed for a device with an antiparallel or reverse diode, this technique has been recently adapted in [13] to a transistor in which the drain voltage can swing negative (the case of a GaN HEMT). Solutions based on the continuum of class-E modes have been also exploited with success, as in [14].

Following the compact approach in [13] and taking advantage of the extracted model, a $700 \mathrm{MHz}$ lumped-element and load-insensitive class-E PA/inverter was designed. For validation of its load modulation/variable resistance operation capabilities, the above mentioned applications (outphasing transmitter and power converter) were addressed through a single implementation.

The schematic and photograph for the outphasing mode are shown in Fig. 3. The compensating reactances in the series non-isolated combiner, together with the output impedance transformer, allow placing the mutual impedance modulation trajectories for efficiently covering a wide dynamic range. When operated as a class- $\mathrm{E}^{2}$ resonant converter, the transformer may be easily disconnected. The Q2 amplifier would turn into its time-reversal dual, a synchronous class-E rectifier, simply substituting its drain voltage supply by a loading dc resistance. Although the compensating reactances could have been avoided, they constitute a series LC circuit resonating at the switching frequency, not affecting the performance.

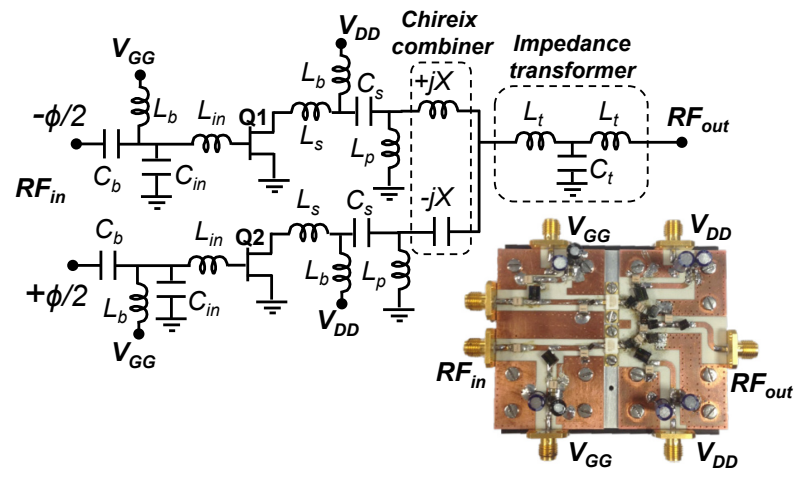

Fig. 3. Schematic and photograph of the implemented topology. 


\section{A. Class-E Outphasing Transmitter}

The class-E based Chireix implementation in Fig. 3 was characterized as a function of the outphasing angle between the $\mathrm{CW}$ driving signals. Measured and simulated results, obtained with the switch-based model, are compared in Fig. 4a, for a $\pm 20 \mathrm{MHz}$ range around $f_{0}=700 \mathrm{MHz}$. A drain efficiency peak of $82.2 \%$ has been measured, while the profile at 720 MHz maintains an efficiency of $71 \%$ at $10 \mathrm{~dB}$ PBO. Fig. 4b shows the measured peak $P_{\text {out }}$ and drain efficiency at different power backoff levels as a function of frequency. Efficiency values higher than $74 \%, 60 \%$ and $43 \%$ have been obtained at 6-, 8-, and 10-dB backoff, respectively.
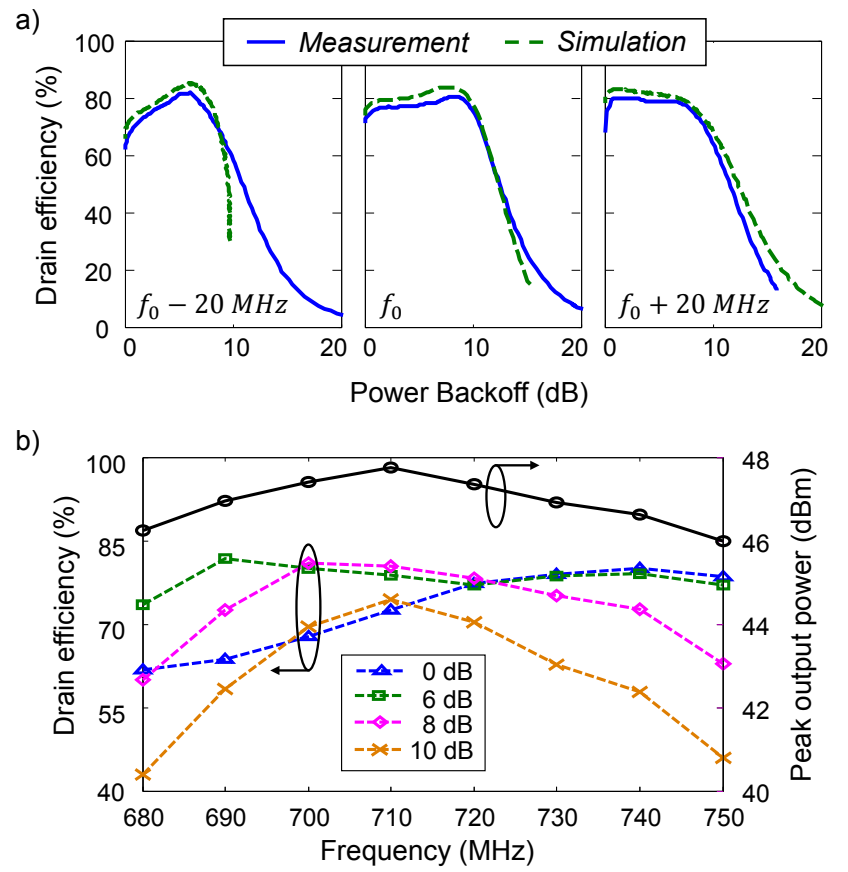

Fig. 4. a) Measured and simulated efficiency profiles at different frequencies for a $20 \mathrm{~dB}$ range of output PBO. b) Measured peak $P_{\text {out }}$ and drain efficiency at different power backoff levels $(0-10 \mathrm{~dB})$ as a function of frequency.

Although not appreciable in Fig. $4 a$, it is remarkable that it would be possible to reproduce envelope values $39.4 \mathrm{~dB}$ below the peak with a pure outphasing operation at $700 \mathrm{MHz}$.

The capability of this narrowband implementation when reproducing complex modulated signals has been also tested using a 1.4 MHz LTE signal with $9.6 \mathrm{~dB}$ of PAPR. It was recovered with an average efficiency of $52.5 \%$ $\left(\eta_{\text {avg_tot }}=49.8 \%\right)$ and $P_{\text {out_avg }}=4.4 \mathrm{~W}$, fitting the linearity requirements for both adjacent and alternate channels through a simple memoryless LUT predistortion procedure. These results are compared with those from representative state-of-theart class-E GaN HEMT outphasing schemes in Table I. If taking advantage from the most efficient static profile at 710 $\mathrm{MHz}$ (see Fig. $4 \mathrm{~b}$ ), a total efficiency close to $56 \%$ could be possible. A more complex DPD technique would be needed.
TABLE I

COMPARISON WITH STATE-OF-THE ART OUTPHASING PAS

\begin{tabular}{|c|c|c|c|c|c|c|}
\hline Ref. & $\begin{array}{c}f_{0} \\
(G H z)\end{array}$ & $\begin{array}{l}\eta_{f 0} @ 6 d B \\
110 d B \\
O P B O(\%) \\
\end{array}$ & $\begin{array}{l}P_{\text {out } \max } \\
(\overline{\mathrm{W}})\end{array}$ & $\begin{array}{l}\mathrm{BW}_{6 \mathrm{~dB}, 60 \%} \\
(\%)\end{array}$ & Signal/PAPR (dB) & $\begin{array}{l}\eta_{\text {avg }} \\
(\%)\end{array}$ \\
\hline This work & 0.7 & $80 / 70$ & 55 & 10 & $\begin{array}{c}1.4 \mathrm{MHz} \text { LTE / } \\
9.6 \mathrm{~dB}\end{array}$ & 52.5 \\
\hline [15] & 0.9 & $80 / 70$ & 24 & $>33$ & $\begin{array}{l}3.84 \mathrm{MHz} \\
\text { WCDMA } \\
/ 6.7 \mathrm{~dB}\end{array}$ & $>70^{*}$ \\
\hline [16] & 2.14 & $60 / 50$ & 110 & 2.4 & $\begin{array}{c}3.84 \mathrm{MHz} \\
\mathrm{WCDMA} / 9.15 \\
\mathrm{~dB}\end{array}$ & 55.6 \\
\hline [14] & 2.3 & $60 / 55$ & 70.6 & 6.5 & $\begin{array}{c}3.84 \mathrm{MHz} \\
\text { WCDMA / } 9.6 \mathrm{~dB}\end{array}$ & 53.5 \\
\hline
\end{tabular}

\section{B. Load-Invariant Class-E2 DC-DC Converter}

After reconfiguring the topology in Fig. 3 to a dc-dc resonant converter, the RF signal driving the rectifying branch was carefully synchronized. The measured and simulated results (using the proposed device model) versus the dc loading resistance are compared in Fig. 5. Such simulation would have not been possible with the nonlinear transistor model, not conceived for reproducing the operation of the rectifying device in the third quadrant of its I/V curves.

An efficiency peak as high as $78 \%$ has been measured at 65 $\Omega$, staying above $60 \%$ up to a $30 \%$ of the nominal dc output power $(10 \mathrm{~W})$. As it was expected from simulations, the dc output voltage keeps close to $29 \mathrm{~V}$ when $R_{L}$ is increased several times above its optimum value. Safe open circuit operation was also verified, as described in [1]. A comparison with illustrative state-of-the-art high frequency dc/dc converters is presented in Table II.

TABLE II

COMPARISON With STATE-OF-THE ART DC-DC CONV.

\begin{tabular}{|c|c|c|c|}
\hline Ref. & $f_{0}(\mathrm{GHz})$ & $P_{\text {out }}(\mathrm{W})$ & $\eta_{\text {peak }}(\%)$ \\
\hline$[6]$ & 0.03 & 220 & 87 \\
\hline$[17]$ & 0.1 & 7 & 91 \\
\hline This work & $\mathbf{0 . 7}$ & $\mathbf{1 0 . 2}$ & $\mathbf{7 8}$ \\
\hline$[18]$ & 1 & 8.5 & 79 \\
\hline$[19]$ & 1.2 & 5 & 75 \\
\hline
\end{tabular}

The demonstrated load-insensitive behavior, approximating a voltage source, would avoid the use of control loops for load regulation. Although usually included in this type of converters, their implementation at UHF band could be highly demanding. This particular feature is highly attractive for its possible use as an envelope modulator.

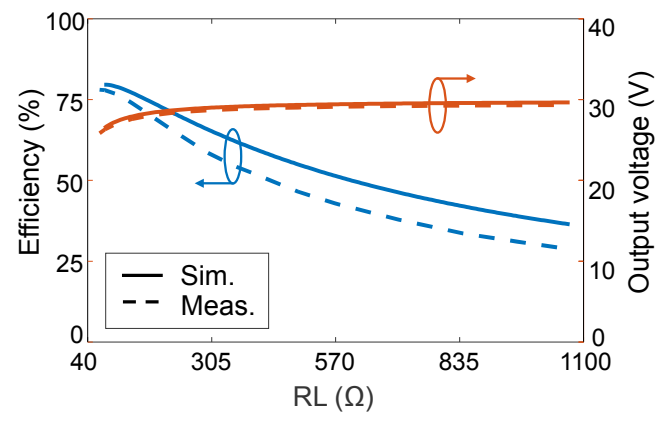

Fig. 5. Simulated (-) and measured (--) efficiency and dc output voltage versus load resistance at $V_{D D}=28 \mathrm{~V}$ and $f=700 \mathrm{MHz}$. 


\section{CONCLUSION}

A switched-based model for a GaN HEMT device has been presented to estimate the output power and efficiency loadpull contours when employed in a class-E PA. A compact lumped-element topology at UHF band has been shown to provide competitive efficiency figures along wide range variable resistive operation. Two different solutions have been reported, using a single implementation: a narrowband outphasing transmitter, able to handle high PAPR signals, and a load-invariant dc-dc resonant converter.

\section{ACKNOWLEDGMENT}

This work was supported by the Ministry of Economy and Competitiveness (MINECO) through TEC2014-58341-C4-1$\mathrm{R}$ and TEC2017-83343-C4-1-R projects, co-funded with FEDER. D. Vegas and M. Pampín also thank the support provided by the pre-doctoral BES-2015-072203 and BES2012-059599 grants, respectively.

\section{REFERENCES}

[1] M. K. Kazimierczuk and X. T. Bui, "Class-E Amplifier with an Inductive Impedance Inverter," IEEE Trans. Industrial Electronics, vol. 37, no. 2, pp. 160-166, April 1990.

[2] F. H. Raab et al., "Power Amplifiers and Transmitters for RF and Microwave," IEEE Trans. Microwave Theory Tech., vol. 50, no. 3, pp. 814826, Mar 2002.

[3] P. M. Lavrador, T. R. Cunha, P. M. Cabral and J. C. Pedro, "The Linearity-Efficiency Compromise," IEEE Microwave Magazine, vol. 11, no. 5, pp. 44-58, Aug. 2010.

[4] H. Chireix, "High Power Outphasing Modulation," Proc. IRE, vol. 23, no. 11, pp. 1370-1392, Nov. 1935.

[5] N. O. Sokal and A. D. Sokal, "Class E, A New Class of High-Efficiency Tuned Single-Ended Switching Power Amplifiers," IEEE J. Solid-State Circ., vol. SC-10, pp. 168-176, June 1975.

[6] J. M. Rivas, O. Leitermann, Y. Han, and D. J. Perreault, "A Very High Frequency DC-DC Converter Based on a Class $\Phi_{2}$ Resonant Inverter," IEEE Trans. Power Electron., vol. 26, pp. 2980-2992, Oct. 2011.
[7] M. K. Kazimierczuk, J. Jozwik, "Resonant DC/DC Converter with Class-E Inverter and Class-E Rectifier," IEEE Trans. Industrial Electronics, vol. 36, no. 4, pp. 468-478, Nov. 1989.

[8] F. H. Raab, "Effects of VSWR upon the Class-E RF-power Amplifier," Proc. RF Expo East '88, Philadelphia, pp. 299-309, Oct. 1988.

[9] R. Beltran, F. H. Raab and A. Velazquez, "HF Outphasing Transmitter using Class-E Power Amplifiers," in IEEE MTT-S Int. Microwave Symp., June 2009, pp. 757-769, Boston, MA.

[10] V. B. Kozyrev, "Single-Ended Switched-Mode Tuned Power Amplifier with Filtering Circuit”(in Russian), Poluprovodnikovye pribory v tekhnike svyazi, vol. 6, pp. 152-166, 1971.

[11] S. C. Cripps, "A Theory for the Prediction of GaAs FET Load-pull Power Contours,” IEEE MTT-S Int. Microw. Symp. Dig., Boston, MA, USA, 1983, pp. 221-223.

[12] J. C. Pedro, L. C. Nunes and P. M. Cabral, "A Simple Method to Estimate the Output Power and Efficiency Load-Pull Contours of Class-B Power Amplifiers," IEEE Trans. Microw. Theory \& Tech., vol. 63, no. 4, pp. 1239-1249, Apr. 2015.

[13] D. Vegas, F. Moreno, M. Nieves Ruiz and J. A. Garcia, "Efficient classE power amplifier for variable load operation," in Int. Integr. Nonlinear Microw. Millimetre-Wave Circuits Workshop, Graz, Austria, Apr. 2017, pp. 1-3.

[14] D. A. Calvillo-Cortes, M. P. van der Heijden, M. Acar, M. de Langen, R. Wesson, F. van Rijs, and L. C. N. de Vreede, "A Package-Integrated Chireix Outphasing RF Swith-Mode High-Power Amplifier," IEEE Trans. Microwave Theory \& Tech., vol. 61, no. 10, pp. 3721-3732, Oct. 2013.

[15] M. Özen, M. van der Heijden, M. Acar, R. Jos, and C. Fager, “A Generalized Combiner Synthesis Technique for Class-E Outphasing Transmitters," IEEE Trans. Circuits Syst. I, Reg. Papers, vol. 64, no. 5, pp. 1126-1139, May 2017.

[16] T. W. Barton and D. J. Perreault, "Four-way Microstrip-based Power Combining for Microwave Outphasing Power Amplifiers," IEEE Trans. Circuits Syst. I, Reg. Papers, vol. 61, no. 10, pp. 2987-2998, Oct. 2014.

[17] Y. Zhang, M. Rodriguez, and D. Maksimovic, "100 MHz, $20 \mathrm{~V}, 90 \%$ Efficient Synchronous Buck Converter with Integrated Gate Driver," IEEE Energy Conv. Congr. and Expo., pp. 3664-3671, Sep. 2014.

[18] J. A. García, R. Marante, M. N. Ruiz et al., "A 1 GHz FrequencyControlled Class E ${ }^{2}$ DC/DC Converter for Efficiently Handling Wideband Signal Envelopes," IEEE MTT-S International Microwave Symposium, 2013.

[19] I. Ramos et al., "GaN Microwave dc-dc Converters," IEEE Trans. Microwave Theory Techn., vol.63, pp. 4473-4482, Dec. 2015. 